\title{
LA BIBLIOTECA DE JUAN DE MAL LARA
}

\author{
Manuel Bernal Rodríguez
}

Los libros que poseía el Maestro Juan de Mal Lara fueron vendidos en Sevilla, en pública almoneda, entre el 29 de marzo y el 5 de abril de 1571, pocos días después de su muerte. Conocemos la relación de esos libros gracias al testimonio que, de la referida almoneda, expidió el escribano público, a petición de María de Ojeda, viuda del humanista. El documento del Archivo de Protocolos de Sevilla en que dicho testimonio se conserva fue dado a conocer por Francisco Rodríguez Marín ${ }^{1}$ y, desde entonces, los estudiosos suelen referirse a la biblioteca de Mal Lara como a cosa conocida.

La preciosa información que nos proporciona el inventario notarial dista mucho, sin embargo, de satisfacer nuestra curiosidad, ya que, si bien nos permite vislumbrar el contenido de la biblioteca, convierte en extremadamente problemática la tarea de averiguar qué libros poseía Mal Lara efectivamente, dificultad habitual, por otra parte, en este tipo de inventarios, dadas su naturaleza y finalidad.

Un estudio que intente desvelar las incógnitas y responder a los numerosos interrogantes que ese documento plantea resulta necesario y, que yo sepa, no ha sido efectuado hasta hoy. Las líneas que siguen pretenden, dentro de los límites de mis reducidas capacidades, cumplir ese ingrato cometido - no en vano M. Chevalier señalaba la necesidad de «mucha paciencia y algo de suerte» para triunfar en tareas como ésta ${ }^{2}$ - . Aunque soy consciente de que he quedado lejos de resolver todas las dificultades, me decido a dar a conocer el resultado de mi trabajo porque creo que permite avanzar algo en el conocimiento del humanista sevillano y de su biblioteca.

En mi opinión, el análisis del inventario sugiere dos tipos de reflexiones, que voy a tratar separadamente.

1 RODRÍGUEZ MARÍN, Francisco, Nuevos datos para ilustrar las biografías de cien escritores de los siglos XVI y XVII, Madrid, 1923, págs. 14-18. Es la base de este trabajo.

2 CHEVALIER, Maxime, Lectura y lectores en la España del siglo XVI y XVII, Turner, Madrid, 1976, pág. 41. 


\section{Dificultad de establecer un catálogo bibliográfico preciso.}

El documento relaciona 76 libros ${ }^{3}$. Dada su finalidad económico-mercantil, el asiento que hace de cada obra dista mucho de lo que entendemos por una descripción bibliográfica y suele constar de una breve alusión al libro, precio en que fue vendido y nombre del comprador; a veces se desliza alguna otra indicación complementaria relativa al tamaño del libro, el idioma en que está escrito, etc.

El problema reside en que la referencia que se da del libro es tan incompleta $\mathrm{y}$, a veces, tan defectuosa, que resulta muy difícil, cuando no imposible, proceder a su identificación. Porque, unas veces, se menciona sólo el autor («un libro de Platón», por ejemplo); otras, únicamente el título; se cometen errores frecuentes al transcribir títulos y nombres de autores; a veces, se alude al libro por un circunloquio que convierte en acertijo la aventura de su identificación, etc., etc. Por supuesto que no se citan editores, ni lugares, ni fechas de edición.

Nos hemos propuesto la tarea de identificar con seguridad, o con el más alto grado de probabilidad, el mayor número de los libros del inventario que nos fuera posible. Los procedimientos seguidos para lograrlo han sido diversos. Unas veces, el objetivo se lograba al subsanar transcripciones defectuosas y, por ejemplo, tras el aparente galimatías de «un juanequio enchilidion», aparecía la obra de ECKIUS, Joannes, Enchiridion locorum communium ${ }^{4}$. Otras, la inconcreción de «un libro pequeño del viaje del príncipe», gracias a una cita de Mal Lara en su Philosophia Vulgar, en su glosa al refrán VI, $63^{5}$, donde dice: «cuéntalo en el Viaje del Príncipe Juan Christóval Caluete», nos conducía a CALVETE DE ESTRELLA, Cristóbal, El felicísimo viaje del Príncipe don Felipe... desde España a sus tierras de la Baja Alemania. En otra ocasión, era la biografía de Mal Lara la que acudía en nuestra ayuda para permitirnos asegurar que la obra que se menciona como «un rregimiento de jueces» no es otra que el Libro nombrado regimiento de jueces del Ldo. Alejo SALGADO CORREA, de quien afirma Mal Lara, Philosophia Vulgar, VI, 33 «que más quiere ser mi amigo que mi señor, aunque para conmigo todo lo es». Por si fuera poco, en elogio de esa obra escribió Mal Lara un epigrama en latín y un soneto en castellano. En otros casos, el idioma en que la obra está escrita facilita su identificación, y así, «un rrudimenta grammatices» casi con toda seguridad se refiere a la obra de Thomas LINACRE de ese título, muy editada en la primera mitad del siglo XVI, y reiteradamente citada por Mal Lara en sus Scholia in syntaxim lilianam ${ }^{6}$, y «un ysmenio en toscano» posiblemente sea la obra que IRVING A. LEONARD registra como «Amo-

3 Chevalier, op. cit., pág. 33, tal vez redondeando la cifra, indica 75.

4 Citada por MARÍN MARTÍNEZ, Tomás, La biblioteca del obispo Juan Bernal Díaz de Luco, Hispania Sacra, 5 y ss.

5 MAL LARA, Juan de, La Philosophia Vulgar, Sevilla, en la calle de la Sierpe, en casa de Hernando Díaz, 1568. Cito siempre por esta edición. El número romano indica la centuria y el arábigo el que corresponde al refrán en cuya glosa se ubica la cita.

6 Sevilla, A. Escrivano, 1567. Fol. 48 ro y 5lro 
res de Ysmenio. (ERISTATHIUS, Macrembolites). En ytaliano. En dos reales» ${ }^{7}$, entre las llegadas a América.

En fin, el conocido erasmismo de Mal Lara nos permite asegurar que, bajo las expresiones «una paráfrasis sobre laurencio», «un conscrivendi epistoli» $\mathrm{y}$ «una copia verborum», se ocultan otras tantas obras del gran humanista holandés ${ }^{8}$.

En resumen, la consulta de los repertorios bibliográficos habituales sobre el siglo XVI ha debido completarse con informaciones derivadas de la lectura de la obra y el estudio de la vida del humanista sevillano. A veces, hasta el precio en que resultó vendida una obra ha constituído un argumento para rechazar o aceptar una posibilidad de identificación ${ }^{9}$.

Combinando, pues, informaciones de diversas procedencias, he confeccionado el catálogo de la biblioteca de Mal Lara, que ofrezco al final de este trabajo. En su redacción he procurado ajustarme a la siguiente metodología: Divido la relación en dos grupos: obras sin identificar y obras probable o seguramente identificadas. Relaciono las obras por orden alfabético de autores o títulos; luego, entre paréntesis, ofrezco textualmente la mención que del libro hace el inventario, seguida del número de orden que en el mismo le correspondería. Es obvio que, con la información suministrada por el documento, resulta imposible — salvo casos excepcionales - aventurar qué edición poseía Mal Lara, ni siquiera en los casos en que estamos totalmente seguros de qué obra se trata. No obstante, cuando describo la obra suelo indicar una edición, siempre anterior a 1571 (Mal Lara falleció a comienzos de ese año); si hay edición sevillana, la prefiero a todas. Indico el catálogo bibliográfico en que he visto la obra descrita y no indico la biblioteca porque en algunos de esos catálogos ya se hace ${ }^{10}$, aunque esa indicación diste mucho de ser completa. En fin, añado testimonios extraídos de la obra de Mal Lara cuando parecen de importancia para ayudar a la identificación de un libro.

\section{Caracterización general de la biblioteca y análisis de la información com- plementaria.}

La información contenida en el documento, además de permitirnos reconstruir, con mayor o menor seguridad, el catálogo de la biblioteca, nos sugiere una serie de reflexiones que merece la pena reseñar.

Cabe señalar, en primer lugar, que, si bien estamos ante una biblioteca a la que puede aplicarse, sin reparos, el calificativo de especializada, no deja de sorprender la elevada diversidad temática que se ha conseguido a pesar del reducido número de títulos, amplitud que tal vez hayamos de considerar como un reflejo

7 LEONARD, Irving A., Los libros del conquistador, Fondo de Cultura Económica, México, 2. ed. 1979, pág. 358.

8 El erasmismo de Mal Lara fue señalado por A. CASTRO «Juan de Mal Lara y su Filosofía Vulgar» en Hacia Cervantes, M. Taurus, 1967, págs. 167 y ss.

9 Según M. Chevalier, Op. cit., pág. 23, los libros vendidos en almoneda resultaban baratos.

10 Así sucede en la publicación de la Biblioteca Nacional Catálogo Colectivo de obras impresas en los siglos XVI al XVIII existentes en las bibliotecas españolas. 
de la universal curiosidad intelectual característica del humanismo. Como corresponde a la biblioteca de un maestro de gramática y latinidad, predominan los textos de los clásicos, los estudios sobre ellos de los humanistas y los tratados gramaticales. Pero, junto a ellos, encontramos libros de carácter misceláneo, tesoros de varia erudición, historias, tratados de espiritualidad, etc., sin que falten libros que reflejan la curiosidad por los temas de actualidad - las Indias, los descubrimientos geográficos, avances de la cosmografía, conocimiento de tierras y gentes exóticas...-, o bien los que tratan de acontecimientos recientes - guerra de Alemania, viaje del Príncipe, etc.- - Por fin, la presencia de algún libro se justifica antes por las relaciones personales del humanista - Regimiento de jueces, por ej.que por su contenido.

Tal vez deba destacarse la presencia de Erasmo - que muy probablemente debió haber sido mayor con anterioridad- como un reflejo de la hoy sobradamente conocida filiación erasmista del maestro sevillano. Sin duda, el férreo control que, por estos años, se ejercía ya sobre la difusión de los escritos del sabio holandés determinó que en la biblioteca sólo quedaran ejemplares de títulos «no comprometedores» ${ }^{11}$.

No siempre resulta posible determinar el idioma en que está escrita cada una de las obras del inventario; no obstante parece posible asegurar que latín y castellano dominan con mucho (más de treinta títulos en cada una de estas lenguas). A ellas debe añadirse una breve representación del italiano, con 4 ó 5 títulos, y una obra en portugués.

Interés especial reviste el análisis de las ausencias. Aunque es un hecho comprobado que las bibliotecas de los intelectuales modestos no alcanzaban un número elevado de volúmenes, en la de Mal Lara no dejan de sorprender algunas ausencias clamorosas que inducen a pensar que, con el paso del tiempo, debió de irse modificando su composición. Sin ánimo de exhaustividad, podrían citarse: - No hay ni un solo ejemplar de las obras publicadas por Mal Lara, lo que resulta más llamativo si se tiene en cuenta que todas ellas habían aparecido en los últimos años de su vida y alguna, -el Recebimiento ${ }^{12}$ - sólo unos meses antes de su muerte.

- Sorprende no encontrar en la biblioteca de Mal Lara algunos textos sobre los que, durante largo tiempo, trabajó asíduamente. Queda constancia de los resultados de ese trabajo y no parece razonable que no hubiera dispuesto de algún ejemplar ${ }^{13}$. Los casos que considero más lla-

11 Quien más detenidamente ha estudiado esta cuestión es F. SÁNCHEZ Y ESCRIBANO, Los «Adagia» de Erasmo en la «Philosophia Vulgar» de Juan de Mal Lara, Hispanic Institute in the United States, 1944.

12 Recebimiento que hizo la muy noble y muy leal ciudad de Sevilla a la C. R. M. del Rey don Philipe, N. S., Sevilla, Escrivano, 1570.

13 Una noticia sobre esos resultados en mi Cultura popular y humanismo. Estudio de la «Philosophia Vulgar» de Juan de Mal Lara, Fundación Juan March, M. 1982. 
mativos son: los Adagia de Erasmo ${ }^{14}$, los Epigramas de Marcial ${ }^{15}$, los Emblemas de Alciato ${ }^{16}$, los refraneros del Marqués de Santillana, Hernán Núñez y Pedro Vallés ${ }^{17}$, sin contar los grandes repertorios de erudición clásica greco-latina que empleó en la redacción de la Philosophia Vulgar $^{18}$.

Otra interesante información se deriva del examen de los nombres de los compradores. Los libros fueron adquiridos por 28 personas distintas, de las que sólo siete compraron las dos terceras partes de la biblioteca (47 libros); de las 21 restantes, 15 compraron un libro, 4 compraron dos y dos adquirieron tres. En principio parece interesante poder identificar la personalidad de los compradores, aunque es tarea dificultosa ${ }^{19}$.

Sólo los nombres de cinco compradores aparecen acompañados de alguna indicación sobre sus estudios o profesión: Jorge de Aragón, estudiante, los licenciados Pineda y Suárez de León ${ }^{20}$, el Doctor Vides ${ }^{21}$ y el Padre Delgado ${ }^{22}$. Entre los restantes, algunos destacan por su personalidad bien conocida; así sucede con Cristóbal Mosquera de Figueroa, discípulo de Mal Lara y autor de la Prefación que había de servir de prólogo a la proyectada edición de la Descripción de la Galera Real ${ }^{23}$. Mucho más famoso, Fernando de Herrera, amigo personal de Mal Lara ${ }^{24}$, que aparece como comprador de «un plinio», «un carolo sigonio»

14 Mal Lara debió tener presente esta obra mientras redactaba su Philosophia Vulgar. V. nota 11.

15 «(Marcial) era de nuestra Hespaña y se puede dezir que el primero que le ha hecho hablar Hespañol so yo». Con estas palabras el maestro sevillano se enorgullece de ser el primer traductor español de Marcial. De su labor quedan las traducciones de 36 epigramas intercalados en las glosas a los refranes de la Philosophia Vulgar.

16 También anunció el humanista una traducción de estos Emblemas. No se conserva como obra independiente, pero buena parte de esas traducciones fueron intercaladas en las glosas a los refranes de la Philosophia Vulgar.

17 Además del refranero del Marqués de Santillana, Mal Lara tenía presentes otras dos obras al redactar las glosas a los refranes de la Philosophia Vulgar: NÚÑEZ, Hernán, Refranes y Proverbios, Salamanca, Juan de Cánova, 1555, obra que sugirió al humanista la idea de escribir la suya, y VALLÉS, Pedro, Libro de refranes compilado por orden del $A B C$. En el qual se contienen quatro mil y trezientos refranes. El más copioso que hasta oy ha salido impresso, Zaragoza, 1549.

18 Entre ellos cabría destacar Johannis Stobei sententiae ex thesauris graecorum delectae, quarum aucthores circiter ducentos et quinquaginta citat..., Basilea, I. Oporini, 1549.

19 He consultado la obra de Mario MÉNDEZ BEJARANO, Diccionario de escritores, maestros y oradores naturales de Sevilla y su actual provincia, 3 vols., Sevilla 1922-1925, con resultados muy pobres.

20 Licenciados de estos apellidos se encuentran entre los vates hispalenses que concurrieron a las justas literarias celebradas en el palacio arzobispal de Sevilla el 1 de diciembre de 1531 y un Agustín Suárez escribió tratados místicos y sermones, según Méndez Bejarano.

21 Un Luis de Vides, indica Méndez Bejarano, erudito del siglo de oro, juntó y escribió muchas noticias relativas a la historia de Sevilla.

22 Un Francisco Delgado, natural de Ecija, figura como provincial sin que se indique la Orden, en el Diccionario de Méndez Bejarano.

23 MAL LARA, Juan de, Descripción de la Galera Real del Sermo. Sr. D. Juan de Austria, Sevilla, Álvarez, 1876. En esa «Prefación», Mosquera nos da una semblanza biográfica de su maestro así como la noticia más antigua que se conserva sobre su obra desaparecida o inconclusa.

24 De esta amistad han quedado testimonios: Herrera escribió un poema en elogio de Mal Lara, que Pacheco incorporó a su semblanza biográfica del humanista en su Libro de Retratos y, en sus 
y un «biaje a tierra santa», títulos estos dos últimos con que se cierra la almoneda. Igualmente famoso, Juan Cromberger, adquiere «un libro de andrés ynperio en 24 maravedís».

De los restantes compradores poco he podido averiguar: Tal vez Antonio Castroverde fuese pariente de otros Castroverde sevillanos, dos de ellos agustinos, Fernando, nombrado obispo de Jaén, y Francisco, que llegó a provincial de Andalucía.

Concluyamos estas divagaciones con el dato curioso de que aproximadamente la mitad de los libros (35) no superaron como precio de venta los dos reales y medio y sólo diez obras superaron los seis reales. El precio total de la venta ascendió a 265 reales y medio.

\section{Catálogo de la Biblioteca.}

A) Autores y obras probable o seguramente identificados.

Los repertorios bibliográficos utilizados han sido los siguientes:

Bataillon, Marcel, Erasmo y España, México, Fondo de Cultura Económica, 2. ed., 1966.

Biblioteca Nacional, Catálogo Colectivo de obras impresas en los siglos XVI al XVIII existentes en las bibliotecas españolas. Sección I. Siglo XVI.

Domínguez GuZMÁn, Aurora, El libro sevillano durante la primera mitad del siglo XVI, Sevilla, 1975.

ESCUDERO y PERosso, Francisco, Tipografía hispalense: anales bibliográficos de la ciudad de Sevilla desde el establecimiento de la imprenta hasta fines del siglo XVIII, Madrid, 1894.

GALlARdo, Ensayo.

LeOnARD, Irving A., Los libros del conquistador, México, Fondo de Cultura Económica, 2. ed., 1979.

Marín Martínez, Tomás, La biblioteca del obispo Juan Bernal Díaz de Luco, en Hispania Sacra, 5 (1952) y ss.

Palau y Dulcet, Antonio, Manual del librero hispanoamericano, Barcelona, 1923-1927, 7 vols.

Estos repertorios aparecerán citados de forma abreviada en la lista que sigue; los que no aparecen en esa lista no se incluyen en esta relación, aunque hayan sido consultados efectivamente.

Amato Lusitano, Diálogo en el cual se trata de las heridas de la cabeza con el casco abierto. Trad. del lat. por Gerónimo Virués. Valencia. Imp. de la Compañía de Libreros, 1558, 8., 308 pp. (PALAU).

(«un libro de amato luçitano, en el doctor vides, en tres rreales».- núm. 22).

Anotaciones a Garcilaso, Herrera se refiere en varias ocasiones a Mal Lara en términos que no dejan lugar a dudas sobre la alta estima en que le tenía. 
Ateneo, Dipnosofistas, o los sabios en el banquete. Citado por Mal Lara en su Philosophia Vulgar, X, 46.

(«yten un ateneo en el licenciado pineda, en quatro rs.».- núm. 10)

Aulo Gelio, Noches áticas. Obra reiteradamente citada en la Philosophia Vulgar, III, 13; V, 21; y VI, 19, 34, 46, 58 y 68.

(«yten un libro de aulo gelio, en el dcho. xpoval mosquera, en tres rreales menos quartillo».- núm. 3).

Ávila y Zuñiga, Luis de, Comentario de la Guerra de Alemania, Amberes, 1550 y muchas eds. posteriores.

(«una guerra de alemania, en el dcho (Andrés de Clavijo), en dos reales y medio», núm.- 61).

Bembo, Pietro, Los Asolanos de Micer----, nuevamente traduzidos de lengua toscana..., Salamanca, 1551 (GALLARDO, Ensayo, II, 71, 1359). PALAU reseña otra ed. salmantina de 1511, a cargo de Andrés de Portonariis.

(«yten las obras de petro blenbo, en el licenciado pineda, en medio ducado», núm. 4). El elevado precio en que se vendió este libro sugiere que pudiera tratarse de un ejemplar que contuviera más de una obra, lo que encajaría bien con el plural empleado en la descripción. cit. en Philosophía Vulgar, IV, 33.

CARICII, Antonio, Gramática francesa. (Citado por Irving A. LEONARD, Los libros del conquistador, Apéndice, Doc. V, pág. 361).

(«un libro pequeño de gramática francesa, en el dcho. francisco de vergara, en medio real», núm.-41).

CeneAu, Roberto. Es difícil pronunciarse por una obra de este autor. En el $C A$ TÁLOGO COLECTIVO hay referencias a ocho obras suyas, editadas entre 1535 y 1558; seis de ellas son de carácter apologético contra los herejes; una, trata sobre pesos y medidas, y otra, de Historia Gallica.

(«un rouerto senal, en el dcho. alonso de arroyo, en un rreal», núm.- 8).

CÉSAR. Las ediciones de Comentarios de César que salen de la imprenta en la primera mitad del XVI son numerosísimas. PALAU y el CATÁLOGO COLECTIVO reseñan muchas. No parece prudente pronunciarse por ninguna en particular. («yten un comentario de sesar, en gerónimo portillo, en dos rreales y medio».núm. 12).

Cicerón, M. Tulio, M. Tull. Ciceronis sententiae illustriores, Apopthegmata item ac Parabolae sive similia aliquot praeterea eiusdem piae sententiae. Authore Petro Lagnerio. Lugduni, 1517, 16.. (CATÁLOGO COLECTIVO).

(«un libro de sentençias de tulio, en el dcho. antonio de maçuelo, en tres rreales».núm. 46). 
Cícerón, M. Tulio, Epistolas.

(«çeletas siceronis, en el dcho. (aluaro gomes) en medio Real».- núm. 71).

Sin duda se trata de las Epístolas, que aparecen como «selectas» en casi todas sus numerosas ediciones (V. PALAU). Con frecuencia se indica que la «selección»se ha hecho con fines didácticos: «in puerorum usu selectae».

Cornelio VAlerio, véase Valerio, Cornelio.

Curcio Rufo, Quinto, Historia de Alexandre Magno. Trad. al castellano por Pedro Cándido Dezimbre, Sevilla, Juan Varela, 1518 (A. DOMÍNGUEZ GUZMÁN).

Escudero Peroso reseña otra edición sevillana de esta obra: Historia de los hechos del magno Alexandre rey de Macedonia, nuevamente traduzido, y suplidos los libros que del faltan de otros autores. (Trad. por G. de Castañeda) Juan Cromberger, 1534, 3. ed. («yten un quinto curçio, en el licenciado xuarez de leon, en rreal y medio».- núm. $15)$.

DATUS, Augustinus, Elegantiae, Valencia, h. 1480. (PALAU reseña otras seis ediciones, entre esta fecha y 1551. Un ejemplar de las Elegantiarum latinarum, 1510, de Agostino DATI, en la Bbca. Univ. de Sevilla).

(«yten un gustino dato, en francisco de rriberol, en tres reales y medio».- núm. 21).

Diógenes Laercio. Debe tratarse de su obra sobre la vida de los filósofos, única, al parecer, por la que se le conoce. Mal Lara cita dos veces a este autor en su Philosophia Vulgar, IV, 72 y III, 57 y, en ambas citas, se alude a la vida de Pítaco Mitileneo.

(«un diogenes laercio, en andrés de clauijo, en quatro rreales».- núm. 56).

ECKIUS, Joannes, Enchiridion locorum communium, 1526, (Citado por Tomás MARÍN MARTÍNEZ, La biblioteca del obispo Juan Bernal Díaz de Luco, en Hispania Sacra, 5 y ss.

(«un juanequio enchilidion, en melchior hurtado, en dos rs.».- núm. 55).

ERASMO, D., De conscribendis epistolis. (Hay ejemplar en la Biblioteca Univ. de Sevilla, Sig.: 84/152).

(«un conscrivendi epistoli, en Juan descalante, en dos rreales».- núm. 31).

ERASmo, D., Erasmi Roterodami... Parabolarum, sive Similium liber, nuper ab eodem recognitus et amendis... perpugnatus. Lovanii, 1515 (En CATÁLOGO COLECTIVO otras cinco eds. Un ejemplar de la de Lugduni, 1528, en la Bbca. Univ. de Sevilla). («un libro pequeño de parabolos de herasmo, en el licenciado pineda, en medio rreal».- núm. 51).

Erasmo, D., Paraphrasis seu potius epitome inscripta D. Erasmo in Elegantiarum libros L. Vallae, París, 1548 (V. BATAILLON, M., Erasmo y España, pág. 830). Mal Lara cita a Valla en Philosophia Vulgar, III, 14.

(«yten una parafracis sobre Laurencio, en el dcho. hernán lópez de gibraleón, en rreal y medio».- núm. 19). 
ERASMo, D., De copia verborum (Dos ejemplares en la Bbca. Univ. de Sevilla, de 1546 y 1565, Sig.: E 66/49 y E 23/141).

(«una copia berborum, en el dcho. ldo. pineda, en un real y un quartillo».- núm. $53)$.

Eristathius, Macrembolites, Amores de Ysmenio. En ytaliano. (V. IRVING A. LEONARD, Op. cit., Apéndice Doc. V, pág. 358).

(«yten un ysmenio en toscano, en el dcho. xpoval. mosquera, en dos rreales».núm. 20).

Escalígero, Julio César, Poética.

(«un césar escalígero, en el padre delgado, en la compañía, en quatro reales», núm.$63)$.

FLORES EPIGRAMMATUM ex optimis quibusque authoribus excerpti per Leodegarium a

Quercu. (Farrago poematum...), Lutetiae, apud Gulielmum Cavellat, 1555. (CATÁLOGO COLECTIVO).

(«un libro de flores epigramatum, en antonio de maçuelo, en ocho rreales».- núm. 45).

Gracián de Alderete, Diego, De re militari (Traducciones de Onosandro, de César y del Señor de Langrey), Barcelona, 1567. (CATÁLOGO COLECTIVO. Citado también por BATAILLON, M., Erasmo y España, LXVII).

(«un libro de rre militari, en rromance, en xpoval. mosquera, en dos rreales».núm. 35).

Herodoto, Herodoti libri novem, quibus Musarum indita sunt nomina. Venetiis. In domo Aldi, 1502. (CATÁLOGO COLECTIVO). Mal Lara, Philosophia Vulgar, V, 26, sigue el relato de Herodoto casi al pie de la letra. Hay doce citas más de la misma obra.

(«un herodoto, en quatro reales, en el dcho. licençiado pineda».- núm. 54).

Heliodoro, Historia ethiópica, trasladada de francés en vulgar castellano por un secreto amigo de su patria, Amberes (Martín Nucio), 1554. (BATAILLON, M., Erasmo y España, LXX).

(«un libro de la ystoria de etiopía, en el dcho. felipe de negro, en çinco rreales».núm. 29).

Historiae Romanae autores varii (V. Velleius Paterculus, L. Florus, Sextus Ruffus, Messala Corvinus, Eutropius). Lugduni, Seb. Gryphium, 1552. (CATÁLOGO COLECTIVO).

(«una ystoria Romana, en el dcho (A. de Clavijo) en dos rs».- núm. 58).

Hyperius, Andreas, F. Andreae Gerardi Hyperii Dominicani cosmographia ad M. Henricum Baldum physicum. Haganoae, 1532. (CATÁlOGO COLECTIVO. Otras obras reseñadas del mismo autor tienen fecha de edición posterior a 1570).

(«Un libro de andrés ynperio, en beinte y quatro maravedís, en juan conberger».núm. 48). 
Jenofonte, Las obras de Xenophonte (Ciropedia; Hiparco; Tratado de la caballería; República de los lacedemonios; La caza). Trad. de Diego Gracián de Alderete. Salamanca, Juan de Junta, 1552. (BATAILLON, Op. cit., LXXIV).

(«un senofonte, en el dcho. (Andrés Clavijo), en siete reales».- núm. 60).

Josefo, Flavio, Josefo de Bello Judaico. Los siete libros de la guerra que tuvieron los judíos con los romanos (...) Trad. y corregido por Alfonso de Palencia. ¿J. Cromberger?, 1522 (A. DOMÍNGUEZ GUZMÁN. Otras dos eds. de Cromberger, de Sevilla, 1532 y 1536).

(«un josefo, en antonio de castroverde, en doce rs.».- núm. 23).

Jovio, Paulo, Elogios o vidas breves de los Caballeros antiguos y modernos. Illustres en valor de guerra, q. están al biuo pintadas en el «Museo» de Paulo Iouio... Tradúxolo de latín en castellano el licenciado Gaspar de Baeça, Granada, 1568. (PALAU).

(«un museo del jobio, en el dcho. felipe de negro, en çinco reales».- núm. 27).

Jovio, Paulo, Historia general de las cosas sucedidas en el mundo..., Salamanca, 1562. (PALAU). Mal Lara, Philosophia Vulgar, IV, 27, se refiere a la Marquesa de Pescara, «cuyos hechos escribe Paulo Jovio en siete libros».

(«un paulo jobio, en el liçençiado pineda, en quinze reales y medio».- núm. 67).

JUSTINO, Justino clarissimo abreuiador de la historia general del famoso y excellente historiador Trogo Pompeyo: en la qual se contienen todas las cosas notables y más dignas de memoria que hasta sus tiempos han sucedido en todo el mundo; agora nueuamente traduzido al castellano (por Jorge de Bustamante). Alcalá de Henares, Juan de Brocar, 1540. (PALAU Y CATÁlOGO COLECTIVO). Citado en la Philosophia Vulgar, VII, 69.

(«un justino, en el dcho. (Andrés Clavijo) en quatro reales».- núm. 59).

Lactancio Firmiano, Lucio Cecilio, De Ira Dei. Mal Lara aduce cita textual de esta obra en su Philosophia Vulgar, I, 31. El CATÁLOGO COLECTIVO ofrece diversas referencias en las que esta obra aparece editada conjuntamente con otras del mismo autor. No he encontrado reseñada ninguna edición independiente de esta obra en la primera mitad del XVI.

(«un libro de latançio firmiano, en el dcho. ldo. pineda, en dos rs».- núm. 52).

LEONI, Nicolás. El bajo precio en que fue vendida esta obra induce a sospechar que se trataba de un opúsculo. Tal vez Nicolai Leoniceni medici clarissimi contra obtrectatores apologia, Venetiis, 1522; o quién sabe si, dada la conocida curiosidad del humanista sevillano por los temas más diversos, pudiera tratarse de Nicolai Leoniceni De serpentibus opus, Bonomae, 1518.

(«un niculás leoni, en el dcho. (Álvaro Gómez) en real y medio».- núm. 73).

LINACRO, Tomás, Rudimenta Grammatices Thomae Linacri..., Lugduni, 1539. (CATÁLOGO COLECTIVO. Otras eds. de 1546 y 1552). Tomás Linacro es una de las autoridades reiteradamente citadas por Mal Lara en sus Scholia in Syntaxim Lilianam (48 r. y 51 ro., p. ej.), así como en los Preámbulos a su Philosophia Vulgar.

(«un rrudimenta gramatices, en Juan diaz, en tres reales».- núm. 13). 
LINACRO, Tomás, Thomae Linacri Britanni, de emendata structura latini sermonis Libri VI, Basilea, 1530. (El CATÁLOGO COLECTIVO reseña siete eds. diferentes, entre 1530 y 1559 ).

(«yten un tomás linacro, en el dcho saluador de los reyes, en noventa e ocho marauedís».- núm. 18).

Lipómano, Luis (LIPPOMANUS, Aloisius). Sanctorum Priscorum Patrum vitae numero sexaginta tres, 4 vols., Venecia, 1551-4. (Tomás MARÍN MARTÍNEZ, Op. cit.). Teniendo en cuenta la descripción que se hace de esta obra en el inventario, debe tratarse de otra edición en la que los cuatro volúmenes aparecieran refundidos en uno solo. («un libro grande de lipomano, en el dcho xpoval mosquera, en beinte Reales».núm. 40).

Macrobio, Las Saturnales. Citada por Mal Lara, Philosophia Vulgar, II, 92.

(«yten un libro de macrobio, en xpoval mosquera, en dos rreales y un quartillo».núm. 2).

\section{Mística Teología.}

(«mística teología, en el dcho (Luis de Ayora)en dos rs., en portugués, los quales traxo que tenía prestados en el dcho». núm. 66).

El dato reseñado del idioma portugués incrementa la dificultad de identificar esta obra. Por lo que valga, IRVING A. LEONARD, Op. cit., Apéndice 2, indica:

«l mistica Teulugia, papelones a 3 reales (Sebastián FOSCARI, Mística Theologia» (pág. 332)).

Paleario, Aonio, Aonii Palearii Verulani De Animorum inmortalitate libri III, Lugduni, 1536. (CATÁlOGO COLECTIVO).

(«yten un aonio palecorio, en aluar gomez de abança, en dos rreales y medio».núm. 7).

Picolomini, Alejandro, Ynstitución de toda la vida del ombre (sic) noble en la qual Peripatética y Platónicamente, acerca de la Ética, Económica y parte de la Política está recopilada la Suma de quanto principalmente puede ocurrir en hazella dichosa y perfeta. Compúsola en lengua toscana Alexandro Picolomini cauallero senés: y tradúxola en vulgar español don Juan de Baraona y de Padilla, natual de Xerez de la Frontera. Sevilla, A. Escriuano, 1577. (ESCUDERO PEROSO, n. 688).

(«un alexandro picolomine, en felipe de negro, en seys rreales».- núm. 24).

Plinio, Cecilio Segundo Cayo (El Joven), Epistolarum libri decem. (CATÁlOGO COLECTIVO registra veinticuatro eds. diferentes de esta obra, en el siglo XVI, desde la de Venecia de 1508). Obra citada por Mal Lara, Philosophia Vulgar, IV, 27.

(«yten las Epístolas de plinio, en gonçalo de herrera, en dos rreales».- núm. 6).

PlinIo, Cayo, Caii Plinii Secundi veronensis naturalis historiae libri XXXVII.

Las eds. de esta obra efectuadas en el s. XVI son muy numerosas. El CATÁLOGO COLECTIVO reseña 52 eds. diferentes; de ellas, todas las españolas son 
incompletas. Entre las registradas por PALAU cabe destacar la anotada por Hernán Núñez Pinciano, habida cuenta de la relación tan directa que, como discípulo, mantuvo con él Mal Lara; se trata, no obstante, de una edición incompleta, que sólo abarca los libros XXV al XXXV. El elevado precio en que fue rematado este libro induce a pensar que se trataba de la obra completa.

(«un plinio, en hernando de herrera, en treze rs.».- núm. 64).

Poliziano, Angelo, Omnia Opera Angeli Politiani, Venecia, 1498. También edición de la obra completa en Basilea, 1553.

La expresa mención de «las obras» y el elevado precio de su venta abonan la hipótesis de que se tratara de la obra completa.

(«primeramente un libro de las obras de poliçiano, en alonso arroyo, en medio ducado».- núm. 1).

Ravisio Textor, Juan, Officina. (Varios ejemplares en la Bbca. Univ. de Sevilla). Obra citada por Mal Lara en su Philosophia Vulgar, VII, 93, y utilizada en múltiples lugares del texto de esa misma obra, se cite o no, como he puesto de manifiesto en mi trabajo Cultura popular y Humanismo. Estudio de la Philosophia Vulgar de J. de Mal Lara, Fundación Juan March, M. 1982.

(«yten un oficina testoris, en el dcho. ldo. pineda, en nuebe rreales».- núm. 11).

RocA, Tomás, Thomae Rocha gottolani digna redargutio I libros tres Augustini ninphi suesani quos ad Karolum Caesarem scripserat. Et incidentaliter gesta militum Hispaniae: contra communitatem, contra Gallos in Navarra. Et eiusdem mira prognosticatio pro anno milesimo quingentesimo vigesimo quarto. Et eiusdem..., Burgos, 1523. (CATÁLOGO COLECTIVO.- PALAU reseña la obra de Vicente ROCCA sobre las guerras de los turcos, que también podría responder a este asiento del inventario). («un empresi militare del rroca, en el dcho. felipe de negro, en seys rreales».- núm. 30).

Salgado Correa, Alexo, Libro nombrado regimiento de jueces, Sevilla, 1556.

De las relaciones que Mal Lara tenía con el autor de esta obra nos ilustra la siguiente cita de la Philosophia Vulgar, VI, 33: «... no puedo dexar de marauillarme de la gran destreza, del que más quiere ser mi amigo que mi señor, aunque para conmigo todo lo es, el licenciado Alexo Correa Salgado... juez en la Casa de la Contratación de Sevilla». Mal Lara escribió para este libro un epigrama en latín, Ioannis Mallarae Hispalensis grammatici epigramma, y un soneto en castellano, Soneto de J. de M., natural de Sevilla, en loor de la obra.

(«un rregimiento de jueces, en bernardino ramires, en diez y ocho mrs.».- núm. 50).

San Gerónimo, Beatissimi Doctoris Hieronymi Apotheosis: ac Beati Augustini Hipponensis Episcopi historia. Compluti. Joannes Brocari, 1544. (PALAU).

(«una aposita de sageromis, en gaspar de medina, en tres rs. menos un quartillo».núm. 68).

SAtUrno, Agustín (SATURNUS, Augustus), Mercurii Maioris Grammaticarum Institutiorum libri decem, Lugduni, 1556. (CATÁLOGO COLETIVO).

(«un agustino saturno, en xpoval garcía, en dos rs.».- núm. 32). 
SÉnECA, Lucio Anneo.

Las ediciones de florilegios de sentencias de Séneca son abundantes. Erasmo fue el colector de uno de ellos, reseñado en el CATÁLOGO COLEC'TIVO, Venecia, 1554; otra edición en PALAU, Amsterdam, 1642. El inconveniente que encuentro para que se tratara de este ejemplar es que no se corresponde el reducido precio en que se remató con la envergadura del volumen. Es más probable que se tratara de la obra siguiente:

Proverbios de Séneca. Trad. de Pedro Díaz de Toledo, Sevilla, Jacobo Cromberger, 1562, 6 hoj. + 62 fol.

El CATÁLOGO COLECTIVO reseña varias eds. de esta obra, así como de Proverbios y sentencias de L. A. Séneca y de don Iñigo López de Mendoça, Marqués de Santillana. Glosado por el Dr. Pedro Díaz de Toledo, Amberes, Juan Steelsio, 1552.

Este último ejemplar resulta también muy poco probable por la misma razón apuntada al comienzo. Cit. en Philosphia Vulgar, I, 55; VII, 23 y X, 78.

(«un libro de sentençias de seneca, en el dcho. francisco de vergara, en medio Real».- núm. 34).

Sigonio, Carolo.

No es fácil decidirse por alguna de sus obras. Tanto por las fechas de edición, como por su contenido, podría tratarse de alguno de sus escritos de carácter histórico o jurídico, así como de los de carácter filológico. El CATÁLOGO COLECTIVO reúne 37 papeletas relativas a otras tantas eds. de sus obras. El único ejemplar conservado en la Bbca. Univ. de Sevilla corresponde a la obra Caroli Sigonii De antiquo Iure civium romanorum Libri duo. Eiusdem de antiquo Jure Italiae Libri tres. Venetiis, 1563.

(«Carolo sigonio, en fernando de herrera, dos rreales».- núm. 75).

SUIDAS.

Sin duda, se trata del famoso Lexicon.

(El CATÁlogo COLECTIVO reseña las eds. de Venecia, 1514, y las de Basilea, 1544, 1546 y 1581). Obra citada en dos ocasiones por Mal Lara en su Philosophia Vulgar, VII, 2 у X, 74.

(«un suydas, en el dcho liçençiado pineda, en dies reales».- núm. 44).

TEUTÓNICO, Juan (Johannes de Friburgo), Summa confessorum reverendi patris Ioannis de Friburgo, Lugduni, 1518. (CATÁLOGO COLECTIVO. También reseña ed. de París de 1519).

(«yten un Juan teutónico, en el dcho hernán lópez de gibraleón, en dos rreales».núm. 16).

Venero, Fr. Alonso, Enchiridion de los tiempos, Sevilla, s. i., 1544; 2. ed., Antón Álvarez, 1547. (A. DOMÍNGUEZ GUZMÁN. Otras eds. en CAT. colectivo).

(«un inquilidion de benero, en luis de ayora, en dos reales».- núm. 65). 
ViAJE DEL PRÍNCIPE.

Calvete de Estrella, Cristobal, El felicísimo viaje del Príncipe don Felipe... desde España a sus tierras de la Baja Alemania, Amberes, 1552. Mal Lara, Philosophia Vulgar, VI, 63, introduce una cita de esta obra con estas palabras: «cuéntalo en el Viaje del Príncipe, Juan Cristóbal Calvete».

(«un libro pequeño del viaje del príncipe, en el dcho. xpoval mosquera, en un real».- núm. 37).

VIneo, Agustín (RAIMUNDO DE CAPUA, Beato), Vita Sanctae Catherinae de Senis, Colonia, 1553. (CATÁlOGO COLECTIVO. Reseña otras ediciones). En la Philosophia Vulgar se relatan anécdotas de la vida de Santa Catalina presumiblemente extraídas de esta obra.

(«yten agustino vineo, en jorge de aragón, estudiante, en quatro rreales».- núm. 5).

ZúÑIgA y Sotomayor, Fadrique de, Libro de cetrería, de caça de açor, en el qual por diferente stilo del que tienen los antiguos que están hechos verán (los que a esta caça fuesen afficionados) el arte que se ha de tener..., Salamanca, Juan de Cánova, 1565, 4, (PALAU).

(«yten un libro de çetrería, en el dcho. francisco de vergara, en medio rreal».núm. 39).

\section{B) Obras en cuya identificación no hemos podido progresar.}

Se relacionan, a continuación, los asientos del inventario en cuya identificación, por causas diversas, no nos ha sido posible avanzar.

1. Autores de obra extensa. Carecemos de datos para decidirnos por alguna de ellas.

AgRícola, Jorge, «yten un jorge agricula, en saluador de los rreyes, en rreal y medio».núm. 14. A Vilanova, Philosophia Vulgar I, 337, nota, supone que se trata de De inuentione dialectica.

DANTE, «un dante, en el dcho (Álvaro Gómez) en dos rreales».- núm. 74.

Flaminio, Marco Antonio, «un flaminio, en el dcho. antonio de maçuelo, en tres rreales».núm. 47.

HAlicARnASo, Dionisio, «un dionisio de alicarnaseo, en el dcho. ldo. pineda, en siete rs.».núm. 43.

Platón, «un libro de Platón, en ocho reales, en el dcho. xpobal mosquera».- núm. 42.

VALERIO, Cornelio, «un cornelio vallerio, en hernán lópez de gibraleón, en dos reales y medio».- núm. 62.

2. No he encontrado obras, editadas en la primera mitad del siglo XVI, que respondan razonablemente a estos títulos: 
— «un aspamia damiani, en el dcho. (Andrés de Clavijo) en dos reales».- núm. 57.

- «un cançionero en romance, en francisco de vergara, en medio real».- núm. 33.

- «un librito pequeño de coloquios de la compañía, en el dcho. hernán lópez de gibraleón, en medio Real».- núm. 36.

— «un comentari de licosi, en el dcho. felipe de negro, en tres rreales».- núm. 28.

- «un libro pequeño de coruto genere, en hernando cauallero, en diez y seis maravedís».núm. 49.

— «un fiori di rretorica, en el dcho. felipe de negro, en cinco rs.».- núm. 26.

— «un libro de Evangelistarium, en el dcho. xpoval mosquera, en 2 rs.».- núm. 38.

— «yten una ystoria de la yndia, en latín, en el licenciado suárez de león, tres rreales».núm. 9.

- «un libro de la ystoria de la yndia oçidental, en el dcho. felipe de negro, en cuatro rs.».- núm. 25. Aunque podría pensarse en la obra de FERNÁNDEZ DE OVIEDO o de LÓPEZ DE GÓMARA, que encajan cronológicamente, no se da una coincidencia en los títulos.

- «unas uino políticas ynstituçiones, en el dcho. (Álvaro Gómez), en beinte y seys mrs.».núm. 70.

— «un poçano y calbiçilans, en el dcho. (Álvaro Gómez), en çinquenta marauedís».- núm. 72.

- «yten un libro de rregibus hispaniae, en el dcho licenciado pineda, en tres rreales menos un quartillo».- núm. 17. ESCUDERO PEROSO registra una Breve compilación en metro de la sucesión de los Reyes de España hasta el rey don Alonso el Sabio, Sevilla, 1549, obra que dista mucho de coincidir con la descrita en el inventario.

- «una rudimenta cosmografie, en alvaro gomez de banca, en medio Real».

- «un biaje a tierra santa», en el mismo, en dos rreales», núm. 76. IRVING A. LEONARD, Op. cit., registra la obra GUERRERO, Francisco, Del viaje de Jerusalén, que no se acomoda a la descrita en el inventario. 
